\title{
- curso de Pedagogia da Universidade Estadual de Ponta Grossa e os nexos entre teoria e prática: uma análise necessária
}

\author{
Sydione Santos ${ }^{1}$
}

\begin{abstract}
RESUMO
O texto apresenta a síntese de um estudo realizado sobre a práxis, no Curso de Pedagogia da Universidade Estadual de Ponta Grossa. Essa investigação abordou um tema já muito discutido, mas ainda problemático na formação de professores: a relação teoria-prática. $\mathrm{O}$ estudo teve como finalidade compreender os pontos críticos dessa relação, evidenciados no desenvolvimento do curso, bem como, buscar na dimensão da prática do pedagogo possíveis elementos articuladores da teoria e da prática. Para compreender os determinantes do problema na sua totalidade, a pesquisa foi realizada através de estudo bibliográfico, análise dos documentos de reformulação, entrevistas com coordenadores e membros do Colegiado, professores e egressos do Curso, culminando na apresentação da Dissertação de Mestrado, em 1998. O trabalho propiciou compreender que significativos avanços foram realizados no Curso de Pedagogia da Universidade Estadual de Ponta Grossa. No entanto, demonstra também a necessidade de redimensionamento do curso no âmbito teórico-prático e as revelações dos sujeitos geram novas discussões a respeito de como o mesmo pode inserir-se, decisivamente, na prática.
\end{abstract}

Palavras-chave: pedagogia, formação do pedagogo, práxis, relação teoriaprática

\footnotetext{
${ }^{1}$ Professora da Universidade Estadual de Ponta Grossa / Departamento de Métodos e Técnicas de ensino. Mestre em Educação.

Olhar de professor, Ponta Grossa, 2 (2):81-93, nov. 1999.
} 
O problema central deste trabalho - o distanciamento entre teoria e prática - explicitou-se a partir das vivências com os estagiários das Habilitações de Magistério, de Séries Iniciais e de Educação Infantil, no curso de Pedagogia, através da disciplina de Prática de Ensino, sob a forma de Estágio Supervisionado.

Essas vivências foram permeadas por reflexões e posicionamentos que possibilitaram a denúncia dos conflitos existentes entre o curso realizado e a prática escolar.

Os conflitos gerados, a partir do estágio, demonstravam a existência de uma prática viva, dinâmica e contraditória, considerando que a escola é um espaço social no qual evidenciamse relações de poder, mecanismos de resistência, pluralidade de idéias e diferentes visões de mundo.

Esse movimento do real oportunizou aos estagiários questionar a estrutura do seu curso de formação, pois, ao se depararem com a prática, necessitavam de elementos teóricos que permitissem compreender a complexidade do processo educativo, potencializando sua ação e tornandoa, assim, reflexiva.

A referida problemática impulsionou esta pesquisa, que se realizou no período de 1995 a 1997 e buscou compreender a trajetória do Curso de Pedagogia da Universidade Estadual de Ponta Grossa. A investigação enfocou as propostas de reformulação gestadas em 1989 e 1996, objetivando analisar os avanços destas no que se refere à articulação do curso com as políticas de formação do educador e com a prática social-concreta efetivada na escola.

A partir dessa compreensão, afirmou-se que os elementos para a necessária reformulação devem ser encontrados na práxis do pedagogo. Assim, ao problematizar a questão, foram levantadas as seguintes hipóteses:

- A não consideração da prática vivenciada pelo pedagogo poderá impedir que o ideal desejado, em termos de projeto de curso, concretize a vivência da teoria na relação teoriaprática.

- Especialmente no momento histórico atual, a Pedagogia, enquanto responsável pela formação teórica do pedagogo, é imprescindível à prática para que esta seja potencializada, tornando-se fonte de conhecimento.

Para a análise dos pontos críticos dessa relação no desenvolvimento do curso, bem como das concepções de homem, sociedade e educação que embasam as propostas de reformulação e a própria práxis do pedagogo, tornou-se necessário fundamentar o estudo na "filosofia da práxis". Nesse âmbito, a práxis é compreendida como atividade real e transformadora, que supera a prática meramente utilitária, numa unidade homem-mundo, matéria-espírito, finalidade-subjetiva e determinismo-objetivo (VÁZQUEZ, 1968).

Dessa forma, entende-se a educação como uma práxis social, orientada por finalidades e pelo conhecimen- 
to, devendo, necessariamente, realizar o papel de mediadora no processo de incorporação crítica da realidade cultural e atingir todos os grupos sociais, sempre na relação com o real.

Esse posicionamento permitiu orientar o estudo no sentido da superação das diferentes visões de teoria e prática, as quais trazem implicações para a formação do educador e para a prática pedagógica.

Foi possível reconhecer que as visões dissociativa e positivo-tecnológica ${ }^{2}$ coexistem e estão presentes nas propostas curriculares desde a implantação oficial dos cursos de formação no Brasil, coadunando-se com a concepção necessária à formação do homem-trabalhador e servindo às finalidades impostas pelos processos de avanço do capitalismo. Explicitam-se assim as dicotomias no Decreto Lei $1.190 / 39$, no Parecer 251/62, na Lei $5540 / 68$, no Parecer 252/69, os quais, ao buscarem ajustar a educação aos planos globais de desenvolvimento e modernização, expressam a lógica da racionalidade técnica, reproduzindo a forma "etapista" de conceber o conhecimento, o que é decorrente das formas de divisão do trabalho, historicamente geradas no interior da vida material.
Para se discutir o entrelaçamento entre pensamento e ação, entre projeto e prática, foram resgatados os estudos realizados pelos movimentos nacionais de educadores, enfatizando especialmente a $\mathrm{ANFOPE}^{3}$, que, na dinâmica da prática educativa/social, produziu conhecimento, lutando por uma política global de formação do educador.

É importante analisar que a re-significação dos Cursos de formação de professores resulta da prática vivenciada no contexto destes. Assim, os estudos e discussões realizados no interior dos movimentos nacionais de educadores denunciam pontos frágeis a serem superados, dentre os quais destacam-se:

- o divórcio entre teoria e prática;

- a separação entre disciplinas de conteúdos e disciplinas pedagógicas;

- estágios curriculares distanciados do curso como um todo;

- desarticulação do ensino, da pesquisa e da extensão;

- currículos propedêuticos e exclusivamente profissionalizantes;

- distanciamento entre as instituições formadoras e os sistemas de ensino;

- ausência de pesquisa;

- desarticulação entre educação e

\footnotetext{
${ }^{2}$ As visões dissociativa e positivo tecnológica inserem-se na concepção dicotômica de teoria e prática. Nesta visão, a ênfase é posta na total autonomia de um pólo em relação ao outro. Este conceito é explicitado por CANDAU (1988), cujos estudos têm fornecido elementos para a análise deste problema na formação de professores.

ASSOCIAÇÃO NACIONAL PELA FORMAÇÃO DOS PROFISSIONAIS DA EUCAÇÃO, reconhecida em 1990, a partir da transformação da comissão Nacional dos Cursos de Formação do Educador.
} 
dinâmica social mais ampla;

- estágio compreendido como prática utilitária e imediatista.

Os pontos abordados pela ANFOPE serviram como elementos de reflexão para auxiliar a análise dos projetos de reformulação do Curso de Pedagogia da UEPG.

No estudo em questão, foram situados dois momentos desse curso: a proposta de 1989, a qual foi uma tentativa de ruptura com o modelo fragmentado de formação, e o projeto de 1996, que foi pensado a partir das contradições geradas pela prática anterior. Considerando que a proposta de 1989 esteve amarrada a determinados referenciais teóricos, expressando uma dada prática, algumas questões se impõem para o desenvolvimento da investigação:

- Em que as duas propostas se diferenciam?

- Que concepções fundamentam a atual proposta?

- Os elementos da prática estão sendo considerados para que a teoria seja potencializada?

- Temos um projeto coletivo e orgânico de curso?

Para tanto, realizou-se o estudo dos documentos de reformulação, o qual foi enriquecido com as informações daqueles que viveram esse processo: coordenadores do Colegiado, professores do curso, representantes discentes, chefes dos Departamentos de Educação e de Métodos e Técnicas de Ensino.

Para confrontar a finalidade (pro- jeto de curso) com a prática (o mundo vivido), buscou-se, nesta investigação, as revelações dos pedagogos formados pela proposta atualmente questionada, visando à compreensão dos pontos críticos da teoria e da prática no interior do curso, os quais não têm possibilitado que se realize uma prática efetivamente transformadora e qualitativamente diferente.

Esses desdobramentos do processo manifestaram a unidade, a síntese de múltiplas determinações que envolvem o problema em questão. $\mathrm{O}$ caminho metodológico exigiu um esforço na busca pela apreensão do objeto de estudo, no sentido de que se fez necessário partir de determinações simples e abstratas para se analisar os conceitos fundamentais que refletem a realidade objetiva e a forma como se relacionam entre si e com o todo, reconstituindo-se assim o concreto "no" e "pelo" pensamento.

\section{A Reformulação de 1989: O iní- cio de Uma Nova Caminhada}

A década de 80 , em decorrência da abertura política e da transição democrática, propiciou debates sobre os problemas nacionais, favorecendo a análise da educação no que se refere às suas políticas, às teorias que fundamentavam a prática pedagógica, aos métodos de ensino, ao funcionamento da escola, enfatizando o papel desta como instrumento de transformação social. 
Em 1989, no contexto do curso de Pedagogia da UEPG, intensificaramse discussões sobre o distanciamento da Universidade em relação à realidade concreta da escola e buscou-se romper com uma prática idealista e ou puramente tecnicista.

Naquele momento, as Associações, os Eventos e os Movimentos de Educadores se fortaleciam, convidando o educador a assumir uma posição crítica frente às propostas unilaterais, definidas à priori pelos órgãos oficiais.

Assim, a reformulação de 1989 propunha a formação de um profissional mais crítico ${ }^{4}$ e mais completo no sentido de atender às exigências da prática docente, voltando-se à formação para o Magistério, porque até então a tônica do curso era formar os "especialistas". Os acadêmicos acabavam preocupados, apenas, em se tornarem um desses profissionais, o que comprometia a sua formação enquanto educador e o necessário conhecimento da prática docente.

Nesse sentido, a CONARCFE 5 apontava para a necessária redefinição de tais profissionais e sinalizava que a docência deveria ser a base da formação do educador.

Cabe lembrar que a mencionada reformulação articulou-se a uma necessidade institucional, que dizia res- peito à anualização dos Cursos Superiores. Dessa forma, a passagem do regime semestral para o anual impulsionou a revisão da grade curricular, não só na sua estrutura, como também quanto aos conteúdos.

Esse repensar trouxe à tona os pontos críticos da relação teoria-prática: a separação entre disciplinas de Fundamentos, Metodologia e Prática de Ensino/Estágio; a falta de respaldo teórico para as questões emergentes no estágio; a dicotomia entre conhecimento na Universidade e conhecimento na escola; a falta de uma linha de trabalho dos Departamentos diretamente envolvidos com o curso.

Os problemas levantados decorrem da forma como foram concebidos os cursos de formação desde a sua origem, cujas raízes encontram-se na sua matriz propedêutica e exclusivamente profissionalizante refletida no Esquema $3+1$, na visão de estágio enquanto aplicação de métodos e técnicas, nas etapas seqüenciais de observação, participação e direção de classe, na concepção de estágio como prática utilitária, incluindo-se ainda a fragmentação do conhecimento decorrente das reformas tecnocratas, a departamentalização e o regime de créditos.

Para solucionar os problemas apontados e formar um pedagogo fun-

\footnotetext{
${ }^{4} \mathrm{O}$ conceito de crítico nesse momento foi decorrente do entendimento da escola como espaço de luta, que se relaciona de forma recíproca com a sociedade, podendo ser um instrumento de transformação social. Este entendimento ultrapassava o pessimismo pedagógico das teorias crítico-reprodutivistas.

${ }^{5}$ Comissão Nacional da Reformulação dos Cursos de Formação de Educadores.
} 
damentado cientificamente, que pudesse atender os conflitos da prática contraditória, foram criadas novas habilitações: Magistério de $1^{\circ}$ grau - Séries Iniciais, Pré-Escola e Alfabetização, mantendo-se a habilitação em Magistério de $2^{\circ} \operatorname{grau}^{6}$. Houve a suspensão temporária das habilitações Administração Escolar, Supervisão Escolar e Orientação Educacional, as quais, após dois anos, foram reabertas com algumas alterações nos conteúdos.

Embora houvesse claramente a intenção de avançar e formar um novo educador, é necessário admitir a fragilidade da proposta ao separar o curso em habilitações distintas, perdendo-se mais uma vez a totalidade da relação finalidade - conhecimento ação, já no processo de formação inicial. Reforça-se, nesse contexto, o isolamento de disciplinas específicas, a falta de trabalho coletivo, o caráter tecnicista e as visões dissociativa/ associativa da teoria e da prática. Reproduz-se, mais uma vez, a maneira etapista da escola trabalhar e organizar o conhecimento na sociedade capitalista (embora já estivessem latentes novas formas de organização do trabalho na esfera produtiva).

A proposta também distanciou-se do posicionamento da CONARCFE (1980/90) que enfatizava a "docência" como fio condutor da formação do educador; e a criação de habilitações agravou o problema da dicotomia teoria - prática no currículo, no trabalho pedagógico e na relação Universidade - Escola.

A outra via para o encaminhamento de mudanças fez-se através da criação da disciplina "Práxis Educativa". Segundo as informações dos professores participantes daquele momento, essa disciplina poderia ser a articuladora da teoria e da prática, integradora do currículo e responsável pela interdisciplinaridade, possibilitando a inserção do acadêmico na escola, desde os primeiros anos do curso.

A intenção da disciplina Práxis Educativa coadunava-se com a proposta da CONARCFE (1989), que apontava para a necessidade de criação de espaços para a integração interdisciplinar ao longo do curso, entendendo que a relação teoria - prática perpassa todas as disciplinas.

Pode-se perceber que, através dessa disciplina, buscou-se, a partir da concretude da prática na escola, problemas reais para serem analisados num processo coletivo, tendo-se a intenção de produzir uma nova prática repensada, explicitando-se a finalidade da Pedagogia: interferir teoricamente na prática.

No entanto, sua finalidade não foi atingida, pois ao se estruturar a práxis numa disciplina, fechou-se o espaço de reflexão e ação coletiva. Cabe di-

\footnotetext{
${ }^{6}$ Serão mantidas as expressões: Pré-Escola, Magistério de $1^{\circ}$ grau e Magistério de $2^{\circ}$ grau, de acordo com a denominação utilizada à época da proposta de reformulação ora investigada
} 
zer que a visão cristalizada de disciplina não permite que se discuta tematicamente os problemas da educação. A disciplina Práxis Educativa acabou também sendo confundida com mais um momento de estágio, apenas antecipado, mas sem articulação com a teoria e com o próprio estágio, realizado na etapa final do curso. O diagnóstico da realidade, realizado no momento da chamada Práxis, não se articulou à disciplina de Métodos e Técnicas de Pesquisa, não possibilitando o sentido da investigação coletiva, num projeto de pesquisa que poderia ser um fio condutor de conhecimento durante o curso.

Apesar disso, a inclusão da referida disciplina foi um avanço naquele momento, porque possibilitou o repensar sobre a formação teórico prática. Porém, a unidade do currículo não pode ser garantida por uma única disciplina e a práxis deve se concretizar no âmbito do curso, a partir da ação coletiva e mediadora entre teoria e prática educacional, tornando a Pedagogia reflexiva e prática no ensino, na extensão e na pesquisa.

Conclui-se que a somatória e a inserção de disciplinas não é o caminho para se recompor a totalidade do curso, enquanto responsável pelo conhecimento e pela intervenção na educação. Isso incide na concepção utilitária de formação de professores e meramente profissionalizante, sem uma política científica.

Sem dúvida, os objetivos traçados para o curso, no documento de reformulação, refletem a preocupação em analisar a educação no contexto como um todo, enfatizando a necessidade do conhecimento sistematizado que possibilitasse o questionamento da estrutura social e da política educacional, embora nos caminhos traçados já estivessem latentes as contradições entre teoria e prática.

Houve esforços no sentido de construir uma teoria que se identificasse com a concretude daquele momento histórico, porém não foi possível construir uma filosofia, um fio condutor que se articulasse a uma concepção de homem sócio-histórico, coerente com uma ação transformadora. Assim, no movimento do real contraditório, vieram à tona novos questionamentos e necessidades. Entende-se, dessa maneira, a prática como critério de validade da teoria, o que permite superar as limitações desta, enquanto atividade teleológica e cognoscitiva (projeção de finalidades e produção de conhecimento em nível de consciência).

\section{A Proposta Atual: Possibilida- de de Práxis?}

A atual proposta de reformulação insere-se no contexto de mudanças pelas quais passa toda a sociedade brasileira/mundial, incluindo-se, decisivamente, as transformações na esfera produtiva. Decorre também da análise das contradições emergentes das propostas anteriores. A necessidade de 
reformulação é resultado da prática gestada no interior das relações entre acadêmicos, professores, colegiado, departamentos, escolas, movimentos de educadores, que se articulam no trabalho realizado no curso.

A proposta esclarece que se faz necessário entender a educação como ação criativa, capaz de produzir um novo homem (capaz de interferir nas mudanças) e uma nova sociedade (justa e emancipatória). Entende-se, nesse processo que, a figura do educador/ mediador é imprescindível enquanto homem situado historicamente, o qual deve ter uma profunda compreensão da realidade do seu tempo e ser comprometido com as mudanças sociais.

Para tanto, busca-se construir um projeto de curso com base no existir humano em sua totalidade, inserido no real histórico. Assim, a proposta objetiva valorizar o pedagogo na sua competência teórica e técnica, junto com o compromisso político; visa garantir os eixos ensino, extensão e pesquisa; privilegia a formação do educador que trabalha no sistema formal de ensino; prioriza a docência como base para a formação do educador, embora não negue as outras funções pedagógicas, que poderão ter lugar após a formação docente.

Intensiona-se que essa reformulação não se constitua numa simples mudança curricular, mas na criação de uma nova proposta de educação, de uma prática educativa, de um novo profissional, baseada na prática coletiva/social.

Dessa forma, a proposta explicita princípios metodológicos para nortear o currículo: base teórica sólida, articulação entre teoria e prática, interdisciplinaridade e prática vivenciada. (Pressupostos decorrentes dos avanços produzidos pela ANFOPE).

$\mathrm{O}$ projeto deixa claro seu posicionamento quanto à qualidade da formação teórica no bojo das relações entre teoria e prática, não criando a falsa crença de que a ênfase na prática é suficiente para a melhoria da formação. Contrapõe-se, portanto, às propostas neo-tecnicistas de formação aligeirada, elaboradas para servir aos reclames das mudanças na esfera produtiva.

É importante reconhecer que a proposta da UEPG volta-se para o espaço escolar e procura desenvolver um curso que não se preocupe apenas com a manutenção ou criação de habilitações, mas que atenda a demanda da população por escolas, considerando o necessário acesso ao conhecimento e sua apropriação.

Essa proposta não deixa de constituir-se numa possibilidade de práxis, a partir do compromisso que estabelece com o ser humano e suas condições de existência. Contudo, a práxis revela-se na prática coletiva do ser social sobre o objeto. Dessa maneira, na concretude da proposta e na ação dos professores e alunos, necessitarão ser definidos, com clareza, os fundamentos, os eixos temáticos, os conceitos norteadores, a metodologia que perpassará o currículo, num movimento que relaciona teoria e prática. Há que se cuidar com a fragilidade inerente à 
grade curricular, ainda organizada pelo conjunto de disciplinas, as quais correm o risco de se tornar isoladas.

As Revelações na Prática do Pedagogo: buscando a Unidade Teoria - Prática

Para se resgatar as necessidades emergentes na prática do pedagogo, foi selecionada uma amostra composta por pedagogos formados no período de 1993 a 1996, egressos da reformulação de 1989, os quais realmente viveram os problemas do curso que hoje é rendimensionado. A amostra constituiu-se de 24 pedagogos atuantes na rede pública e particular, nas funções de Professor, Supervisor Escolar, Orientador Educacional e Diretor de Escola. Considerou-se $10 \%$ do número de pedagogos formados em cada ano, no período acima mencionado.

Foi utilizada a técnica da entrevista semi-estruturada. As entrevistas desenvolveram-se através de perguntas desencadeadoras, que possibilitaram, a partir dos posicionamentos, a elaboração de categorias como: concepção de homem e sociedade, finalidade, conhecimento e prática. Estas categorias foram interpretados em três eixos, entendendo-se que as reais necessidades da prática do pedagogo são re-significadas a partir da totalidade das questões, em função do sentido da categoria práxis:

\section{- As concepções de homem e so- ciedade que norteiam a prática em função das necessidades}

Sendo a prática orientada pela finalidade, enquanto antecipação ideal em nível de consciência, e considerando-se que é uma necessidade do homem afirmar o que ainda não existe, em função dos desafios da realidade objetiva, tornou-se necessário, ao se analisar a práxis, resgatar a concepção de homem e de sociedade inclusa nas finalidades que orientam a prática do pedagogo.

Nesse sentido, os pedagogos revelaram compreender os desafios presentes na sociedade conflituosa e em permanente processo de mudanças, preocupando-se com o impacto do desenvolvimento tecnológico nos processos sociais e com as profundas modificações na organização do trabalho, que alteram as formas de concepção do conhecimento. Preocupam-se em formar um novo trabalhador, flexível intelectualmente, criativo, capaz de usar o conhecimento com qualidade e que precisa estar continuamente buscandoo, considerando a sua provisoriedade. Daí a necessidade de se rever as concepções e os métodos de ensino.

No entanto, os pedagogos entrevistados não limitam a formação do homem para o trabalho, deixando explícita a necessidade de formar o sujeito capaz de superar as desigualdades, sabendo tomar decisões para o bem comum; o cidadão reflexivo, comprometido com uma sociedade 
justa e digna; o homem de caráter, capaz de recuperar valores positivos para toda a humanidade.

As respostas revelam que a sua prática está permeada por tensões entre a formação para o trabalho e a formação de um homem emancipado, entre competitividade e igualdade, entre cliente/trabalhador e cidadão, entre a redefinição do humanismo da modernidade e a pluralidade do pósmodemismo. Contudo, preocupam-se com a escola enquanto espaço privilegiado de educação e colocam a urgência de sua redefinição desta no sentido de olhar as múltiplas dimensões do homem, ultrapassando a visão de currículo por disciplinas estanques, o que não dá conta da formação na contemporaneidade.

O pedagogo, egresso da reformulação de 1989, tornou-se, na sua práxis, um profissional preocupado em considerar as diferentes vozes, em trabalhar as contradições e repensar finalidades. Assim, evidenciam-se os encontros e desencontros da teoria e da prática, da sua ação e do curso que realizou.

- A relação entre finalidade, conhecimento e ação: contribuições e dificuldades do Curso de Pedagogia

A atividade da consciência não se restringe somente à prefiguração de resultados, mas também se manifesta na produção de conhecimentos que permitem a apropriação da realidade e a criação de novas formas de compreensão desta. A finalidade projetada depende do conhecimento do objeto a ser transformado, dos meios e dos instrumentos para a ação, o que implica a necessidade de base teórica sólida na relação com a prática, durante o processo de formação do educador.

Foi possível reconhecer, no decorrer da investigação, que as dificuldades sentidas na prática vão ao encontro daquelas apontadas, em função da análise da reformulação de 1989, demonstrando que o esquema curricular propedêutico não resiste ao novo, ao imprevisível, tornando a teoria frágil e desvinculada da prática.

Após a análise das dificuldades apontadas, foi possível retomar duas teses, a de que a prática é critério de validade da teoria e a do professor como profissional reflexivo, capaz de construir e reconstruir o conhecimento, através dos processos de conhecimento na ação, reflexão na ação, reflexão sobre a ação e sobre a reflexão na ação. ${ }^{7}$

É importante também reconhecer a contribuição do curso e os avanços realizados nesta trajetória, pois na relação da teoria com a prática contraditória, os pedagogos egressos demonstram a intenção de buscar continuamente o conhecimento e tor-

\footnotetext{
${ }^{7}$ Processos analisados por Donald SCHON, que embasam estudos sobre a formação do professor reflexivo.
} 
naram-se capazes de questionar o contexto em que se inserem. Ressaltam a necessidade de investigação na sua prática e buscam possibilidades de formação contínua (Cursos de Especialização, Mestrado, Complementação em outras habilitações ainda em funcionamento).

- A prática como fonte de teoria: o resgate das necessidades reais

Todas as questões anteriormente analisadas incluem-se na necessidade primordial do curso: inserir-se decisivamente na prática educativa.

Os pedagogos esclarecem que suas dificuldades poderão ser melhor enfrentadas a partir do momento em que o curso preocupar-se com as suas ações enquanto profissionais da educação a quem compete intervir na prática educativa, nela inserindo-se.

Isso significa que há que se considerar como este profissional vive e sente a sua própria prática, que tipo de relações se estabelecem no espaço educativo, qual conhecimento é trabalhado e de que maneira é assimilado. Enfatizam a responsabilidade da Universidade na sua formação teórica inicial e contínua, entendendo a teoria como conhecimento sistematizado e como meio para intervenção na prática.

Compreendem o curso de Pedagogia como fundamental à prática educativa, devendo ser responsável por tornar claro a própria "práxis do pedagogo", fundamentando cientificamente esse trabalho, especialmente através da pesquisa/produção de conhecimento.

Além do pedagogo compreender os processos educativos e neles intervir, entende-se que deve produzir conhecimento pedagógico, contribuindo para a re-significação das práticas educativas. Essa responsabilidade é reconhecida pelos pedagogos quando citam que a Universidade deve produzir conhecimento e que a instituição deve usar do poder de "fazer refletir".

É sentido que os pedagogos cobram a relação mais estreita entre Universidade, escola e problemas educacionais. $\mathrm{O}$ curso é responsabilizado e chamado a estar junto às "reformas" e às mudanças propostas para a educação, auxiliando o profissional a compreender, enfrentar e questionar a educação e os processos que lhe são inerentes, num contexto significativo, concreto e situado historicamente.

As revelações descritas e interpretadas neste trabalho permitiram comprovar as hipóteses levantadas a partir do problema. Ainda tornou-se possível considerar que as finalidades da proposta atual para o curso articulamse às finalidades que permeiam a ação do pedagogo, porém, isso implica a construção contínua e coletiva deste projeto. É preciso desafiar-se a trabalhar com as contradições e diferentes vozes a partir do real, reconhecendo a complexidade das relações entre finalidade, conhecimento e ação, en- 
tre teoria e prática.

Assim, o coletivo do curso estará buscando a construção de uma concepção necessária à formação do homem, o qual deverá continuar o processo de humanização, para que todos tenham acesso a uma vida digna e feliz.

\section{REFERÊNCIAS}

BIBLIOGRÁFICAS

1 ASSOCIAÇÃONACIONAL PELA FORMAÇÃO DOS PROFISSIONAIS DA EDUCAÇÃO. Documento Final: II Encontro Nacional. Niterói, 1994.

2 . Documento Final. VIII Encontro Nacional. Belo Horizonte, 1996.

3 _. Formação de professores: dilemas e perspectivas. s/d. Mimeo.

4 Pedagogia, pedagogos e formação de professores. Campinas: Papírus, 1996.

5 CANDAU, Vera M. Rumo a uma nova didática. Petrópolis: Vozes, 1988.

6 COMISSÃO NACIONAL DE REFORMULAÇÃO DOS CURSOS DE FORMAÇÃO DE EDUCADORES. Coletânea de Documentos. Coordenação Nacional. Brasília. Setembro/1988.

7 COMISSÃO NACIONAL DE REFORMULAÇÃO DOS CURSOS DE FORMAÇÃO DO EDUCADOR. Documento Final. Belo Horizonte, Julho, 1989.
8 Documento Final. Belo Horizonte, Julho, 1990.

9 CURY, Carlos Roberto Jamil. Educação e contradição. 3. ed. São Paulo: Cortez, 1987.

10 FREITAS, Helena Costa Lopes de. O trabalho como princípio articulador na prática de ensino e nos estágios. Campinas: Papirus, 1996.

11FREITAS, Luiz Carlos de. Críticas da organização do trabalho pedagógico e da didática. Campinas: Papirus, 1995.

12 GRAMSCI, Antonio. Os intelectuais e a organização da cultura. Rio de Janeiro: Civilização Brasileira, 1979.

13 Concepção dialética de história. Rio de Janeiro: Civilização Brasileira, 1981.

14 KONDER, Leandro. O futuro da filosofia da práxis: o pensamento de Marx no século XXI. Rio de janeiro: Paz e Terra, 1992.

15 KOSIK, Karel. Dialética do concreto. Rio de Janeiro: Paz e Terra, 1976.

16 MANACORDA, Mário Alighiero. Marx e a pedagogia moderna. São Paulo: Cortez: Autores Associados, 1991.

17 MOREIRA, Antonio Flávio B. Currículos e programas no Brasil. Campinas: Papirus, 1990.

18 NAGLE, Jorge. Educação e sociedade na primeira república. São Paulo: EPU, 1974. 
19 NÓVOA, Antonio. Os professores e a sua formação. Lisboa: Publicações Dom Quixote, 1992.

20 PICONEZ, Stela Bertholo (coord). A prática de ensino e o estágio supervisionado. Campinas: Papirus, 1991.

21 PIMENTA, Selma G. O estágio na formação de professores: unidade teoria-prática? São Paulo: Cortez, 1995.

22 (org.) Pedagogia, ciência da educação? São Paulo: Cortez, 1996.

23 PROJETO DO CURRÍCULO PARA O CURSO DE LICENCIATURA EM PEDAGOGIA E HABILITAÇÕES (Seriado Anual), Universidade Estadual de Ponta Grossa, 1989. (Mineo)

24 PROPOSTA DE REFORMULAÇÃO DO CURSO DE PEDAGOGIA. Universidade Estadual de Ponta Grossa, 1996. (Mimeo)

25 PROPOSTA DE MANUTENÇÃO E REFORMULAÇÃO DAS HABILITAÇÕES ESCOLAR， ORIENTAÇÃO EDUCACIONAL E SUPERVISÃO ESCOLAR NO CURRÍCULO DO CURSO DE PEDAGOGIA Universidade Estadual de Ponta Grossa, DEMET, 1990. (Mimeo)

26 RIBEIRO, Maria Luiza Santos. Educação escolar e práxis. São Paulo: Iglu, 1991.
27 S C H M I E D - K O WA R Z I K, Woldietrich. Pedagogia dialética - de Aristóteles a Paulo Freire. São Paulo: Brasiliense, 1983.

28 VÁZQUEZ, Adolfo Sánchez. Filosofia da práxis. Rio de Janeiro: Paz e Terra, 1968.

29 WARDE, Mirian J. et al (org) 0 Banco Mundial e as políticas educacionais. São Paulo: Cortez, 1996. 